\title{
How addicted are newly admitted undergraduate medical students to smartphones?: a cross-sectional study from Chitwan medical college, Nepal
}

\author{
Sirisa Karki ${ }^{1 *}$, Jaya Prasad Singh², Gita Paudel ${ }^{1}$, Sushma Khatiwada ${ }^{3}$ and Sameer Timilsina ${ }^{4}$
}

\begin{abstract}
Background: Increasing smartphone use among adolescents in todays' world has made this handy device an indispensable electronic tool, however, it comes at a price of problematic overuse or addiction. We aim to investigate the prevalence of smartphone addiction among undergraduate medical students and explore its association with various demographic and personal factors.

Methods: A pool of 250 undergraduate students completed a survey composed of socio-demographics information, smartphone-use related variables and 10-point Smartphone Addiction Scale-Short Version in February 2019.

Results: Smartphone addiction among medical students was estimated at around 36.8\% with higher percentage of male smartphone addicts. Phubbing was reported by $37.6 \%$ participants with more than $60 \%$ reporting overuse. Statistically significant association was observed between smartphone addiction and gender and overuse. Self-acknowledgement of addiction was found to be the biggest predictor of smartphone addiction.

Conclusion: This study provides preliminary insights into smartphone use, smartphone addiction and various factors predicting smartphone addiction among early undergraduate medical students from Nepal, which should be extended in future studies. Education policymakers and educators need to develop some strategies encouraging student's smartphone utilization to enhance academic performance.
\end{abstract}

Keywords: Smartphone, Addiction, Undergraduate, Medical

\footnotetext{
* Correspondence: karki.sirisa@cmc.edu.np; sirisa.karki@gmail.com

'Department of Pharmacology, Tribhuvan University, Chitwan Medical College, Post Box No: 42, Bharatpur-5, Chitwan, Nepal

Full list of author information is available at the end of the article
}

(c) The Author(s). 2020 Open Access This article is licensed under a Creative Commons Attribution 4.0 International License, which permits use, sharing, adaptation, distribution and reproduction in any medium or format, as long as you give appropriate credit to the original author(s) and the source, provide a link to the Creative Commons licence, and indicate if changes were made. The images or other third party material in this article are included in the article's Creative Commons licence, unless indicated otherwise in a credit line to the material. If material is not included in the article's Creative Commons licence and your intended use is not permitted by statutory regulation or exceeds the permitted use, you will need to obtain permission directly from the copyright holder. To view a copy of this licence, visit http://creativecommons.org/licenses/by/4.0/. The Creative Commons Public Domain Dedication waiver (http://creativecommons.org/publicdomain/zero/1.0/) applies to the data made available in this article, unless otherwise stated in a credit line to the data. 


\section{Background}

With the advancement in science and technology, the way we live, our life style and everything including the way we remain connected to people, has changed drastically. The advances in telecommunication means has evolved our lives from simple to becoming simply complicated. Technology has enabled people to access the previously thought inaccessible information at ones' fingertips.

As of recent times, people living in the lesser developed world have encompassed a massive transformation in mobile and internet technology. Smartphone has reached a substantial 2.1 billion people worldwide [1]. Studies have shown that young children as less as 2 years to 17 years use smartphone more than the older generation, although its ownership increases with age [2]. In Nepal, Nepal Telecom (Nepal Doorsanchar Company Limited) is the incumbent operator, owned by the government of Nepal that provides the telecommunication services. Internet service started with the beginning of the century and in less than 17 years, its penetration has reached over $58 \%$ and rising $[3,4]$.

Increasing smartphone use among adolescents in todays' world has made this handy device an indispensable electronic tool. Smartphone applications can be applied in education, [5] health [6], smoking cessation [7], alcohol usage monitoring [7] and virtual reality therapy [8]. However, it comes at a price of problematic overuse or addiction. Individuals with prolonged and excessive smartphone use present with symptoms like self-absorption, inability to control craving, disturbances in daily schedule ignoring adverse consequences and withdrawal. These presenting symptoms are similar to those observed in patients with "Substance-Related and Addictive Disorders" as described in Diagnostic and Statistical Manual of Mental Disorders (DSM-5) [9]. Like pathological gambling, which actually has been stated in DSM-5 as behavioral addiction, internet gaming disorder and smartphone addiction are on line awaiting sufficient evidence [9]. Several studies conducted across the world show addiction of children, adolescents and university students to the smartphone. Students use smartphone as a tool for studying, communicating with friends and family and study purpose. Easy internet connectivity along with user-friendly advanced technology help students easily access required study materials. On the other hand, despite of its apparent benefits, excessive smartphone and internet use can lead to anxiety, [10] attention deficit [11], sleep disturbance, [12] poor quality of life, [13] and poor academic growth. Smartphone addiction has been investigated among medical students reporting hindrance to academic activities and overall growth and performance. In the present study, we aim to evaluate the status of smartphone addiction among medical undergraduate students of Chitwan Medical College and study its association with various demographic variables.

\section{Methods}

A total of 250 first year undergraduate students at Chitwan Medical College, Bharatpur, Nepal were recruited from the pool of "School of Medicine", "School of Dental Surgery", "School of Nursing" and "School of Allied Sciences". All 261 first year undergraduate students enrolled at the college were invited to participate in the study in February 2019, but only 95.7\% (250) of students entered the survey. Prior to the survey, researcher briefed the students about the objectives and procedure of the study. The participants were also informed about the voluntary nature of participation and non-participation would not bear any academic consequences. A written consent was obtained from the students for participation in the study. Ethical clearance for the study was obtained from Institutional Review Committee of Chitwan Medical College (ref no: CMC-IRC/075/076-123). The first section of the survey included demographic information (age, gender, faculty, duration of smartphone-use per day during weekdays, purpose of smartphone use, and self-evaluation of smartphone addiction) and the second section included a 10 item shorter version of smartphone addiction scale (SASSV). Participants were instructed to rate the items on a 6-point Likert scale, 1 = "strongly disagree", 2 = "disagree", $3=$ "slightly disagree", $4=$ "slightly agree", $5=$ "agree" and $6=$ "strongly agree" so that the addiction score ranged from 10 to 60 . As recommended by the guideline, an overall score of greater than 33 in males and greater than 31 in females was considered addiction [14]. The SAS-SV considers 5 parameters of smartphone addiction; 1 . Disturbance in daily life (3 questions), 2. Withdrawal (4 questions), 3. Overuse (1question), 4. Tolerance (1 question) and 5. Virtual relationship (1 question). Using smartphone for longer than $5 \mathrm{~h}$ daily during weekdays was labeled as "overuse". The purpose of smartphone use included 3 multiple choice options namely communication, social networking and gaming and study purposes. Participants were also instructed to self-evaluate their addiction status. Statistical analysis was done using SPSS-20. Numerical values were expressed as mean \pm SD and categorical variable as percentage. Chi-square test was used to seek association between demographic variables in addicted and non-addicted samples. Logistic regression analysis was performed for multivariate analysis to seek the association between smartphone-use variables and smartphone -addiction. 


\section{Results}

The study included 250 undergraduate students: $38.8 \%$ males $(97 / 250)$ and $61.2 \%$ females (153/250) with mean age of $19.7 \pm 1.68$ years (range 18-29 years). The pool of participants included 87 students from school of medicine, 51 from school of dental surgery, 96 from school of nursing and 16 from school of allied sciences.

Most of the participants (224) attended private or boarding schools before joining medical school. 74\% (185) of the participants currently resided in hostel. Smartphone was commonly found to be used for communication, social networking, gaming and study purposes (26.8\%). 26.8\% (67/250) of the participants self-rated themselves as addicted to smartphone, $42 \%$ $(105 / 250)$ did not rate themselves as addicted and the rest $31.2 \%(78 / 250)$ had no opinion of the same (Table 1).

Indications of disturbance in daily life was reported by over $60 \%$ participants. The study also reported nomophobia among $72.4 \%$ of participants. Likewise, phubbing was reported among $37.6 \%$ participants. Overuse was reported by $60.8 \%$ participants. Tolerance was observed in $42.8 \%$ participants who accepted peoples concern about excessive smartphone use (Table 2).

Smartphone addiction was found among 36.8\% (92/ 250) of the participants with equal numbers of male and females (46). A higher percentage of males were found to be addicted to smartphones $(\mathrm{M}=47.42 \% \mathrm{~F}=$ $30.06 \%)$. The average addiction score among males was $30.23 \pm 9.40$ and that among females was $28.89 \pm$ 8.63. A higher average addiction score was obtained among females.

Participants using smartphone for communication, study, gaming and social networking had the higher addiction scores $(40.37 \pm 6.04)$. Participants accepting self-addiction reported highest addiction scores followed by those who used smartphones for longer duration during weekdays (Table 3 ).

Among 92 smartphone addicted participants, 44 $(65.7 \%)$ had self-rated themselves positively for addiction. 15(14.3\%) participants who did not self-accept were found to be addicted, and 33 (42.3\%) of those who did not opine were addicted to smartphone. Smartphone addiction was found to be associated with gender, duration of use and self-acceptance of smartphone addiction. It was not associated with faculty, past educational institute and place of residence at current time (Table 4).

Male undergraduate medical students were more likely to be addicted than females (OR: 1.99). Selfacceptance of addiction was the biggest predictor of smartphone addiction among the studied variable (OR: 11.088) (Table 5).
Table 1 Characteristics of study participants

\begin{tabular}{|c|c|}
\hline Variables & Frequency (\%) \\
\hline \multicolumn{2}{|l|}{ Gender } \\
\hline Male & 97 (38.8\%) \\
\hline Female & $153(61.2 \%)$ \\
\hline \multicolumn{2}{|l|}{ Faculty } \\
\hline School of medicine & $87(34.8 \%)$ \\
\hline School of Dental Surgery & $51(20.4 \%)$ \\
\hline School of Nursing & $96(38.4 \%)$ \\
\hline School of Allied sciences & $16(6.4 \%)$ \\
\hline \multicolumn{2}{|l|}{ Past Educational Institute } \\
\hline Private/ Boarding School & $224(89.6 \%)$ \\
\hline Government/ Public School & $26(10.4 \%)$ \\
\hline \multicolumn{2}{|l|}{ Place of residence } \\
\hline Hostel & 185(74\%) \\
\hline Day-scholar & $65(26 \%)$ \\
\hline \multicolumn{2}{|l|}{ Reasons for using Smartphone } \\
\hline Communication & $16(6.4 \%)$ \\
\hline Social networking and gaming & $23(9.2 \%)$ \\
\hline Studying & $12(4.8 \%)$ \\
\hline $\begin{array}{l}\text { Communication, social networking } \\
\text { and gaming }\end{array}$ & $25(10 \%)$ \\
\hline $\begin{array}{l}\text { Social networking, gaming and } \\
\text { study purposes }\end{array}$ & $59(23.6 \%)$ \\
\hline Communication and study & $48(19.2 \%)$ \\
\hline $\begin{array}{l}\text { Communication, social networking, } \\
\text { gaming and study purposes }\end{array}$ & $67(26.8 \%)$ \\
\hline \multicolumn{2}{|l|}{ Self-Perception of Smartphone addiction } \\
\hline Yes & $67(26.8 \%)$ \\
\hline Don't Know & $78(31.2 \%)$ \\
\hline No & 105 (42\%) \\
\hline \multicolumn{2}{|l|}{ Duration of Smartphone use (weekdays) } \\
\hline$>5 \mathrm{~h} /$ weekdays & $42(16.8 \%)$ \\
\hline$\leq 5 \mathrm{~h} /$ weekdays & $208(83.2 \%)$ \\
\hline
\end{tabular}

\section{Discussion}

The smartphone technology is sweeping the world at an alarming rate but the advancement comes at a price; the risk of jeopardizing social life and being addicted to the virtual world. The mobile phone penetration in Nepal is $123 \%$ with mobile internet penetration around 58\% [2]. The fondness of owning, overusing and engaging in virtual social life has massively engulfed the youth of the twenty-first century. In the present study, the smartphone was owned by all 250 (100\%) participants. Smartphone addiction was found to be around $36.8 \%$ similar to a study among adolescents in India [9] but slightly higher than prevalence of internet addiction (30\%) 
Table 2 Prevalence of smartphone addiction (SAS-SV) symptoms among study participants

\begin{tabular}{|c|c|c|}
\hline Symptoms & Items & n (\%) \\
\hline \multirow[t]{4}{*}{ Disturbance in daily life } & I have missed planned work due to Smartphone use. & $108(43.2)$ \\
\hline & I have a hard time concentrating in class, while doing my assignments & $64(25.6)$ \\
\hline & or while working due to Smartphone use. & \\
\hline & I feel pain in the wrist or on the back of my neck due to smart phone use. & $98(39.2)$ \\
\hline \multirow[t]{4}{*}{ Withdrawal } & I will not be able to stand not having a Smartphone. & $142(56.8)$ \\
\hline & I feel impatient and fretful when I am don't have my Smartphone with me. & $109(43.6)$ \\
\hline & I have Smartphone on my mind even when I am not using it. & $73(29.2)$ \\
\hline & $\begin{array}{l}\text { I will not give up using my Smartphone even when my daily life is already } \\
\text { greatly affected by it. }\end{array}$ & $36(14.4)$ \\
\hline Virtual relationship & $\begin{array}{l}\text { I constantly check my Smartphone so as not to miss conversation between } \\
\text { other people on twitter, Facebook, Viber, WeChat, snapchat. }\end{array}$ & $94(37.6)$ \\
\hline Overuse & I feel like I am using my Smartphone more than I had intended. & $152(60.8)$ \\
\hline Tolerance & The people around me tell me that I use my Smartphone too much. & $107(42.8)$ \\
\hline
\end{tabular}

among medical students worldwide [15]. The similarity could have been because of similar socio-economic conditions. Nomophobia (72.4\%) reported in the present study was inconsistent with previous studies. The difference in the timing of the study could have been the reason for this discrepancy with earlier studies reporting a much lower prevalence. Earlier, smartphone and internet penetration was reportedly low. Moreover, lack of validated questionnaire could as well have reported contrasting results but a rapid rise has been reported in recent studies with some studies among medical students reporting addiction as high as 92\% [14]. Anxiety of separation, and loneliness at the start of medical school could as well contribute to smartphone addiction and nomophobia [16]. Similar findings have been reported from China [17] and Lebanon [18].

Our study reported pain in the wrist or on the back of neck due to excessive smart phone use among 39.2\% participants. This may lead to future physiological and psychological complications. The result of the present study reported a higher percentage of male to female smartphone addicts similar to a study among Iranian and Chinese medical students but unlike others reporting higher female addiction [17, 19, 20]. The evolution of internet and smartphone based games and its gaining popularity among males could be a cause of such a finding $[18,21]$. Our present study reported that females used smartphones mostly for communication and social networking. Males used smartphone mostly for communication and gaming concurrent with a study from China [17]. The similarity could have been a result of parallel nature of either gender of similar age and field of study. The present study is not in a situation to speculate the similarity and a need for further studies is recommended to resolve the inconsistent prevalence of smartphone addiction among gender. More internet and gaming addiction studies could prove such a finding in Nepal's context.

Studies have shown a higher number of females accepting smartphone addiction than male participants similar to present study [19]. However, the present study reported a higher male mean addiction score than females $(30.23 \pm 9.40: 28.89 \pm 8.63)$.

Studies have shown bidirectional influence of smartphone and psychiatric conditions. Some suggest smartphone addiction can cause insomnia, restlessness, stress, depression and impulsive behavior, [22, 23] whereas some studies show these disorders could facilitate smartphone addiction [24]. These conflicting evidences warrant further studies. In the present study, we postulated impulsive overuse of smartphone as probable cause of smartphone addiction. Using smartphone for more than $5 \mathrm{~h}$ a day during weekdays and selfperception of being addicted to smartphone were found to be corelated with smartphone addiction. This finding was similar to the one reported in Lebanon [18]. Excessive use could be a sign of addiction and carefree nature. Almost 43\% participants reported being complained about excessive use of smartphone by people nearby. The present study reported smartphone overuse among $16.8 \%(42 / 250)$ participants and its association with addiction similar to a study among medical students in Iran. The similarity could have been a result of homogenous sample population [25]. In the present study, the participants were instructed to self-report their duration of smartphone use where participants could have had difficulty recalling the past. This recall bias is one of the limitations of this study. 
Table 3 Smartphone addiction (total SAS-SV) and participants' characteristics

\begin{tabular}{|c|c|c|}
\hline Parameters & $\begin{array}{l}\text { Overall SAS-SV } \\
\text { score mean } \pm \text { SD (n) }\end{array}$ & $\begin{array}{l}\text { Addiction Score } \\
\text { mean } \pm \text { SD (n) }\end{array}$ \\
\hline \multicolumn{3}{|l|}{ Gender } \\
\hline Male & $30.23 \pm 9.40(97)$ & $38.21 \pm 5.63(46)$ \\
\hline Female & $28.89 \pm 8.63(153)$ & $39.36 \pm 5.45(46)$ \\
\hline \multicolumn{3}{|l|}{ Faculty } \\
\hline School of Medicine & $30.29 \pm 9.23(87)$ & $38.49 \pm 5.50(39)$ \\
\hline School of Dental Surgery & $28.66 \pm 10.85(51)$ & $40.69 \pm 7.10(17)$ \\
\hline School of Nursing & $28.34 \pm 7.35(96)$ & $38.10 \pm 3.47(28)$ \\
\hline School of Allied Sciences & $30.62 \pm 10.09(16)$ & $38.86 \pm 4.54(8)$ \\
\hline \multicolumn{3}{|l|}{ Past Educational Institute } \\
\hline Private/ Boarding School & $29.67 \pm 9.17(224)$ & $39.06 \pm 5.58(85)$ \\
\hline Government/ Public School & $27.15 \pm 6.30(26)$ & $35.42 \pm 3.65(7)$ \\
\hline \multicolumn{3}{|l|}{ Reasons for using Smartphone } \\
\hline Communication & $24.43 \pm 5.09(14)$ & $33.11 \pm 0.63(2)$ \\
\hline Social networking and gaming & $28.34 \pm 8.43(23)$ & $38.41 \pm 3.92(7)$ \\
\hline Studying & $28.91 \pm 6.30(12)$ & $34 \pm 2.99(5)$ \\
\hline Communication, social networking and gaming & $26.44 \pm 9.12(25)$ & $36.50 \pm 5.07(8)$ \\
\hline Social networking, gaming and study purposes & $28.77 \pm 9.49(59)$ & $38.98 \pm 6.54(20)$ \\
\hline Communication and study & $29.64 \pm 7.85(48)$ & $37.77 \pm 3.88(18)$ \\
\hline $\begin{array}{l}\text { Communication, social networking, gaming } \\
\text { and study purposes }\end{array}$ & $32.56 \pm 9.59(67)$ & $40.37 \pm 6.04(34)$ \\
\hline \multicolumn{3}{|l|}{ Duration of Smartphone use / weekday } \\
\hline$>5 \mathrm{~h}$ & $32.66 \pm 10.04(42)$ & $39.72 \pm 6.95(23)$ \\
\hline$<=5 \mathrm{~h}$ & $28.75 \pm 8.58(208)$ & $38.46 \pm 5.01(69)$ \\
\hline \multicolumn{3}{|l|}{ Self-Perception of Smartphone addiction } \\
\hline Yes & $35.55 \pm 8.18(67)$ & $39.80 \pm 6.66(44)$ \\
\hline No & $25.17 \pm 6.87(105)$ & $36.86 \pm 2.74(15)$ \\
\hline Don't Know & $29.85 \pm 8.94(78)$ & $38.26 \pm 4.45(33)$ \\
\hline \multicolumn{3}{|l|}{ Residence at present time } \\
\hline Hostellers & $28.81 \pm 8.80(185)$ & $38.89 \pm 5.18(32)$ \\
\hline Day-scholars & $31.92 \pm 9.20(65)$ & $38.72 \pm 5.79(60)$ \\
\hline
\end{tabular}

Self-acceptance was another factor most closely associated with smartphone addiction reinforcing the fact that self-admission and self-esteem had direct effect on mobile phone addiction. Self-acceptance was found to be the biggest predictor of smartphone addiction. This was consistent with study from Korea [23] unlike from China [26].

The study showed a significant association between gender and smartphone addiction $(p<0.01)$ unlike one reported in India as recent as 2016 [27]. The association could have been observed because of larger female sample population. More such studies are necessary to confirm such fact. Previous educational institute namely government or private academic institutions showed no correlation with smartphone addiction in either sexes.

Decreasing tendency of smartphone addiction with progressive year has been observed in India [28, 29]. Further studies involving all level of undergraduate students is recommended to establish such a fact.

Studies have shown the use of smartphone for learning purpose as a protective factor over unproductive use for smartphone addiction [30,31]. In our study only 12/250 $(\mathrm{M}=5$ and $\mathrm{F}=7)$ participants used smartphone solely for study purpose. This could as well be a reason for higher percentage of smartphone addiction in the current study. Use of smartphone for social networking was the commonest cause of smartphone addiction. 
Table 4 Association between smartphone addiction and participants' characteristics

\begin{tabular}{|c|c|c|c|c|}
\hline \multirow[t]{2}{*}{ Variable } & \multicolumn{2}{|l|}{ Addiction } & \multirow[t]{2}{*}{$x^{2}$} & \multirow{2}{*}{$\begin{array}{l}p- \\
\text { value }\end{array}$} \\
\hline & Addicted $n$ & Not-addicted $n$ & & \\
\hline Gender & & & 7.690 & 0.006 \\
\hline Male & 46 & 51 & & \\
\hline Female & 46 & 107 & & \\
\hline Faculty & & & 6.278 & 0.099 \\
\hline School of Medicine & 39 & 48 & & \\
\hline School of Dental Surgery & 17 & 34 & & \\
\hline School of Nursing & 28 & 68 & & \\
\hline School of Allied Sciences & 8 & 8 & & \\
\hline Past Educational Institute & & & 1.217 & 0.270 \\
\hline Private/ Boarding School & 85 & 139 & & \\
\hline Government/ Public School & 7 & 19 & & \\
\hline Duration of Smartphone use / weekday & & & 7.003 & 0.008 \\
\hline$>5 \mathrm{~h}$ & 23 & 19 & & \\
\hline$<=5 \mathrm{~h}$ & 69 & 139 & & \\
\hline Self-Perception of Smartphone addiction & & & 47.915 & $<0.001$ \\
\hline Yes & 44 & 23 & & \\
\hline No & 15 & 90 & & \\
\hline Don't Know & 33 & 45 & & \\
\hline Residence at present time & & & 41.145 & 0.420 \\
\hline Hostellers & 32 & 153 & & \\
\hline Day-scholars & 60 & 5 & & \\
\hline
\end{tabular}

\section{Conclusion}

Smartphone addiction was common among the investigated medical students. Excessive use of smartphone may lead to the risk of addiction. Responsible use can benefit individuals and any form of addiction can be checked by a strong will. We suggest a need for intervention to reduce smartphone addiction among undergraduate medical students probably incorporating health education about the use of mobile phone. Young people

Table 5 Multiple Logistic Regression between smartphone-use variables and addiction

\begin{tabular}{|c|c|c|c|c|}
\hline Variable & B & $p$-value & OR & $95 \% \mathrm{Cl}$ \\
\hline \multicolumn{5}{|l|}{ Gender } \\
\hline Male & 0.688 & 0.027 & 1.990 & $1.082-3.65$ \\
\hline Female & & & 1 & \\
\hline \multicolumn{5}{|c|}{ Duration of Smartphone use / weekday } \\
\hline$>5 \mathrm{~h}$ & 0.157 & 0.690 & 1.17 & $0.541-2.531$ \\
\hline$<=5 \mathrm{~h}$ & & & 1 & \\
\hline \multicolumn{5}{|c|}{ Self-Perception of Smartphone addiction } \\
\hline Yes & 2.406 & $<0.001$ & 11.088 & $5.715-24.039$ \\
\hline Don't know & 1.331 & & 3.786 & $1.835-7.814$ \\
\hline No & & & 1 & \\
\hline
\end{tabular}

should be advised and educated about conscientious use of smartphone to avoid detrimental impact on daily life. Further studies will be required to reveal smartphone addiction in different levels of education.

\section{Abbreviation}

SAS-SV: Smartphone addiction scale- short version

\section{Acknowledgements}

We would like to thank CMC-IRB for allowing us to conduct this study. We would also like to thank fellow colleagues of School of Medicine, Chitwan Medical College for all the help and support. Our sincere gratitude to Mr. Uttam Malla and Dr. Prashant Malla for helping us proofread the manuscript. Nonetheless, our sincere gratitude to all the participants in the study without whom this study would not have been possible.

\section{Authors' contributions}

SK1 conceptualized the study, participated in formulating study tool, wrote the manuscript and helped in revising the draft. JPS analyzed the data, helped in formulating the initial draft and helped in revising the draft. GP and SK2 assisted in data collection, re-writing the manuscript and revising the draft. ST obtained ethical approval, collected data from the participants, re-wrote the manuscript and assisted in data analysis. All authors read and approved the final manuscript.

\section{Funding}

No funding was available for the study. The investigators shared the cost of the study. 


\section{Availability of data and materials}

The datasets obtained and/or analyzed during the current study are not publicly available due to confidentiality consent of the study but can be obtained from the corresponding author on reasonable request.

\section{Ethics approval and consent to participate}

Ethical approval was obtained from Institutional Review Board of Chitwan Medical Collge, Bharatpur-10, Chitwan, Nepal (ref no: CMC-IRC/075/076-123). Written consent was obtained from all the participants for participation in the study. The consent also informed the participants that the data obtained could be used and made public under anonymity. All procedures were in accordance with the Helsinki declaration and its later amendments.

\section{Consent for publication}

Not applicable.

\section{Competing interests}

The authors declare that they have no competing interests.

\section{Author details}

'Department of Pharmacology, Tribhuvan University, Chitwan Medical College, Post Box No: 42, Bharatpur-5, Chitwan, Nepal. ${ }^{2}$ School of Public Health, Chitwan Medical College, Bharatpur-5, Chitwan, Nepal. ${ }^{3}$ Department of Anatomy, Tribhuvan University, Chitwan Medical College, Bharatpur-5, Chitwan, Nepal. ${ }^{4}$ Department of Physiology, Tribhuvan University, Chitwan Medical College, Bharatpur-5, Chitwan, Nepal.

Received: 16 August 2019 Accepted: 21 February 2020

Published online: 02 March 2020

\section{References}

1. Bae SM. Smartphone addiction of adolescents, not a smart choice. J Korean Med Sci. 2017:32(10):1563-4.

2. Lauricella AR, Cingel DP, Blackwell C, Wartella E, Conway A. The Mobile generation: youth and adolescent ownership and use of new media. Commun Res Rep. 2014:31(4):357-64.

3. Gautam DK. NTC and Ncell: telecommunication and strategies. South Asian J Bus Manag Cases. 2016;5(1):126-33.

4. Nepal Telecom. Introduction to telecommunications in Nepal. Kathmandu: Nepal Telecom; 2017. Available from https://www.ntc.net.np/about-us/ nepal-telecom-in-brief. [cited 202025 Feb].

5. Zhang MW, Ho CS, Ho RC. Methodology of development and students' perceptions of a psychiatry educational smartphone application. Technol Health Care. 2014;22(6):847-55

6. Do TT, Le MD, Van Nguyen T, Tran BX, Le HT, Nguyen HD, Nguyen LH, Nguyen CT, Tran TD, Latkin CA, et al. Receptiveness and preferences of health-related smartphone applications among Vietnamese youth and young adults. BMC Public Health. 2018;18(1):764.

7. Tran BX, Le XTT, Nguyen PN, Le QNH, Mai HT, Nguyen HLT, Le HT, Tran TT, Latkin CA, Zhang MWB, et al. Feasibility of e-health interventions on smoking cessation among Vietnamese active internet users. Int J Environ Res Public Health. 2018;15(1):165.

8. Zhang MW, Ho RC. Smartphone applications for immersive virtual reality therapy for internet addiction and internet gaming disorder. Technol Health Care. 2017;25(2):367-72.

9. Hasin DS, O'Brien CP, Auriacombe M, Borges G, Bucholz K, Budney A, Compton WM, Crowley T, Ling W, Petry NM, et al. DSM-5 criteria for substance use disorders: recommendations and rationale. Am J Psychiatry. 2013:170(8):834-51.

10. Do HN, Onyango B, Prakash R, Tran BX, Nguyen QN, Nguyen LH, Nguyen HQT, Nguyen AT, Nguyen HD, Bui TP, et al. Susceptibility and perceptions of excessive internet use impact on health among Vietnamese youths. Addict Behav. 2020;101:105898.

11. Ho RC, Zhang MW, Tsang TY, Toh AH, Pan F, Lu Y, Cheng C, Yip PS, Lam LT, Lai CM, et al. The association between internet addiction and psychiatric co-morbidity: a meta-analysis. BMC Psychiatry. 2014;14:183.

12. Zhang MWB, Tran BX, Huong LT, Hinh ND, Nguyen HLT, Tho TD, Latkin C, Ho RCM. Internet addiction and sleep quality among Vietnamese youths. Asian J Psychiatr. 2017;28:15-20.

13. Tran BX, Huong LT, Hinh ND, Nguyen LH, Le BN, Nong VM, Thuc VTM, Tho TD, Latkin C, Zhang MW, et al. A study on the influence of internet addiction and online interpersonal influences on health-related quality of life in young Vietnamese. BMC Public Health. 2017;17(1):138.

14. Kwon M, Kim D-J, Cho H, Yang S. The smartphone addiction scale: development and validation of a short version for adolescents. PLoS One. 2014;8(12):e83558.

15. Zhang MWB, Lim RBC, Lee C, Ho RCM. Prevalence of internet addiction in medical students: a meta-analysis. Acad Psychiatry. 2018;42(1):88-93.

16. Kim HI, Cheon SH, Kang HJ, Lee K, Jung SP. Associations between smartphone addiction scale and sociopsychological aspects in medical school students. Yeungnam Univ J Med. 2017;34(1):55-61.

17. Chen B, Liu F, Ding S, Ying X, Wang L, Wen Y. Gender differences in factors associated with smartphone addiction: a cross-sectional study among medical college students. BMC Psychiatry. 2017;17(1):341.

18. Matar Boumosleh J, Jaalouk D. Depression, anxiety, and smartphone addiction in university students- a cross sectional study. PLoS One. 2017; 12(8):e0182239.

19. Demirci K, Akgonul M, Akpinar A. Relationship of smartphone use severity with sleep quality, depression, and anxiety in university students. J Behav Addict. 2015;4(2):85-92.

20. De-Sola Gutiérrez J, Rodríguez de Fonseca F, Rubio G. Cell-phone addiction: a review. Front Psychiatry. 2016;7:175.

21. Fam JY. Prevalence of internet gaming disorder in adolescents: a metaanalysis across three decades. Scand J Psychol. 2018;59(5):524-31.

22. Richardson M, Hussain Z, Griffiths MD. Problematic smartphone use, nature connectedness, and anxiety. J Behav Addict. 2018;7(1):109-16.

23. Lee J, Sung M-J, Song S-H, Lee Y-M, Lee J-J, Cho S-M, Park M-K, Shin Y-M. Psychological factors associated with smartphone addiction in south Korean adolescents. J Early Adolesc. 2018;38(3):288-302.

24. Aker S, Sahin MK, Sezgin S, Oguz G. Psychosocial factors affecting smartphone addiction in university students. J Addict Nurs. 2017;28(4):215-9.

25. Mohammadi S, Valinejadi A, Saman JA, Karimpour H, Kaivanfar M, Safaeipour $M$, et al. Assessment of addiction to internet, smartphone and social networks among students of medical sciences: a cross sectional study. Electron J Gen Med. 2018;15(4):em35. https://doi.org/10.29333/ejgm/85685.

26. You Z, Zhang $Y$, Zhang $L, X u Y$, , Chen $X$. How does self-esteem affect mobile phone addiction? The mediating role of social anxiety and interpersonal sensitivity. Psychiatry Res. 2019:271:526-31.

27. Rupani M. Cross-sectional study on mobile phone involvement among medical students of a tertiary care teaching hospital of western India. Natl J Commun Med. 2016;7:609-13.

28. Domple V, Wadde S, Gattani P. Mobile phone dependence among undergraduate medical students in Nanded city. Ann Trop Med Public Health. 2017;10(1):27-30.

29. Loredo ESMP, de Souza Matos BD, da Silva EO, Lucchetti ALG, Lucchetti G. The use of smartphones in different phases of medical school and its relationship to internet addiction and learning approaches. J Med Syst. 2018:42(6):106.

30. Boumosleh J, Jaalouk D. Smartphone addiction among university students and its relationship with academic performance. Global J Health Sci. 2017; 10(1):48.

31. Lee H, Kim JW, Choi TY. Risk factors for smartphone addiction in Korean adolescents: smartphone use patterns. J Korean Med Sci. 2017;32(10):1674-9.

\section{Publisher's Note}

Springer Nature remains neutral with regard to jurisdictional claims in published maps and institutional affiliations.

\section{Ready to submit your research? Choose BMC and benefit from:}

- fast, convenient online submission

- thorough peer review by experienced researchers in your field

- rapid publication on acceptance

- support for research data, including large and complex data types

- gold Open Access which fosters wider collaboration and increased citations

- maximum visibility for your research: over $100 \mathrm{M}$ website views per year

At $\mathrm{BMC}$, research is always in progress.

Learn more biomedcentral.com/submission 